\title{
SISTEM PENDUKUNG KEPUTUSAN DALAM MENENTUKAN PENERIMA PROGRAM KELUARGA HARAPAN (PKH) DI NAGARI AIA BATUMBUAK MENGGUNAKAN METODE ANALITHICAL HIERARCHY PROCESS (AHP)
}

\author{
Veni Wedyawati ${ }^{1)}$, Eko Amri Jaya ${ }^{2)}$, Marya Nelsa Achsani ${ }^{3)}$ \\ Sistem Informasi, Sekolah Tinggi Teknologi Industri Padang \\ Email : venywedyawati@sttind.ac.id ${ }^{1)}$, ekoamrijaya@sttind.ac.id ${ }^{2)}$, \\ maryanelsaachsani@gmail.com ${ }^{3)}$
}

\begin{abstract}
Abstrak
Abstrak: Sistem pendukung keputusan secara umum didefenisikan sebagai sebuah sistem yang mampu menghasilkan pemecahan masalah. Sistem pendukung keputusan tidak dimaksudkan untuk menggantikan peran pengambil keputusan, tapi untuk membantu dan mendukung pengambil keputusan. Salah satu metode yang sering digunakan dalam sistem pengambilan keputusan adalah metode Analithichal Hierarchy Process (AHP). Metode AHP ini dipilih karena metode ini dapat menguraikan masalah multi faktor atau multi kriteria yang kompleks menjadi suatu hirearki. Dengan hierarki tersebut suatu masalah akan tampak lebih terstruktur dan sistematis. Program keluarga harapan $(\mathrm{PKH})$ adalah salah satu bantuan yang diberikan pemerintah kepada masyarakat kurang mampu yang memenuhi syarat untuk dapat menerima bantuan berupa uang tunai. Dengan metode Analithichal Hierarchy Process (AHP) tersebut diharapkan penilaian akan mendapatkan hasil yang lebih maksimal. Sistem pendukung keputusan ini dirancang dengan menggunakan bahasa pemrograman visual basic.net.
\end{abstract}

Kata kunci: SPK, AHP, PKH, kurang mampu

Abstract: Decision support systems (SPK) are generally defined as a system capable of producing problem solving. Decision support systems are not intended to replace the role of decision makers, but to help and support decision makers. One method that is often used in decision-making systems is the method of analytic hierarchy process (AHP). This AHP method was chosen because this method can describe complex multi-factor problems or multi criteria into a hierarchy. with a hierarchy a problem will appear more structured and systematic. The family hope program $(P K H)$ is one of the assistance provided by the government to the underprivileged people who are eligible to receive cash assistance. With the analithal hierarchy process (AHP) method, it is expected that the assessment will get maximum results. This decision support system is designed using visual basic.net programming language.

Keywords: SPK, AHP, PKH, underprivileged

\section{PENDAHULUAN}

Kemiskinan merupakan masalah utama dan komplek setiap negara. Kemiskinan tidak mungkin dapat dihapuskan oleh negara manapun, tetapi dengan tekad yang kuat, kemiskinan dapat ditekan atau diminimalkan. Untuk meminimalisir permasalahan kondisi sosial, terutama mengenai kemiskinan yang terus meningkat setiap hari maka Pemerintah Indonesia melalui Kementerian Sosial mengeluarkan Program Keluarga Harapan (PKH). Selama ini di Nagari Aia Batumbuak proses penentuan penerima bantuan program keluarga harapan $(\mathrm{PKH})$ tersebut 
masih dilakukan secara manual, sehingga banyak terjadi kesalahan seperti penerima bantuan yang tidak tepat sasaran atau tidak sesuai dengan kriteria yang telah ditentukan.

Kehilangan data juga sering terjadi karena data yang diberikan oleh calon penerima $\mathrm{PKH}$ tersebut hanya berupa lembaran kertas yang mudah tercecer atau hilang. Selain itu faktor kekeluargaan juga menjadi salah satu faktor yang menyebabkan penerima PKH tidak sesuai dengan harapan.

Agar bantuan Program Keluarga Harapan (PKH) ini tepat sasaran dan berjalan sesuai dengan rencana sehingga menghasilkan hasil yang maksimal dan mencapai tujuan yang ingin dicapai pemerintah, diperlukan sebuah aplikasi atau program yang dapat membantu pemerintah Nagari Aia Batumbuak di dalam memutuskan siapa yang berhak menerima bantuan Program Keluarga Harapan (PKH) tersebut. Berdasarkan penjelasan diatas, penulis mengangkat sebuah judul "Sistem Pendukung Keputusan Dalam Menentukan Penerima Program Keluarga Harapan (PKH) di Nagari Aia Batumbuak Menggunakan Metode Analytichal Hierarchy Process (AHP)"

\section{METODE PENELITIAN}

Jenis penelitian yang digunakan dalam penyusunan penelitian ini adalah yang bersifat terapan yaitu penelitian yang diarahkan untuk mendapatkan informasi yang dapat untuk memecahkan masalah. Tujuan dilakukan penelitian terapan untuk menerapkan, menguji dan mengevaluasi masalah-masalah sehingga hasil yang didapat bisa dimanfaatkan untuk kepentingan manusia baik secara individu maupun secara kelompok. Penulis juga melakukan observasi langsung ke tempat objek pokok permasalahan yang akan dibahas.

Kegiatan penelitian yang penulis lakukan ini berlokasi di Kantor Wali
Nagari Aia Batumbuak Kecamatan Gunung Talang, Kabupaten Solok.

Data primer atau data langsung merupakan metode pengumpulan data dilakukan oleh peneliti dengan metode wawancara (Interview) dan metode pengamatan (Observasi). Data sekunder adalah data yang diperoleh dari literatur, jurnal-jurnal dan studi kepustakaan yang berhubungan dengan penelitian dan mendukung penelitian ini.

Sumber data penelitian ini berasal dari pengamatan langsung pada Nagari Aia Batumbuak dan data yang di peroleh dari Kantor Wali Nagari Aia Batumbuak.

\section{HASIL DAN PEMBAHASAN}

1. Menu Login

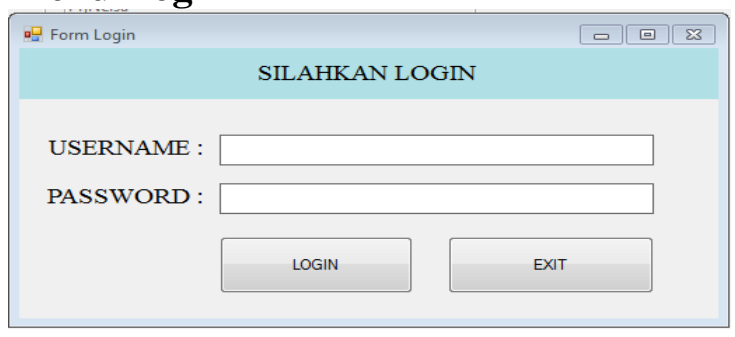

Gambar 1 Menu Login

\section{Menu Utama}

Master Data Laporan Logout

Gambar 2 Menu Utama

\section{Data Kartu Keluarga}

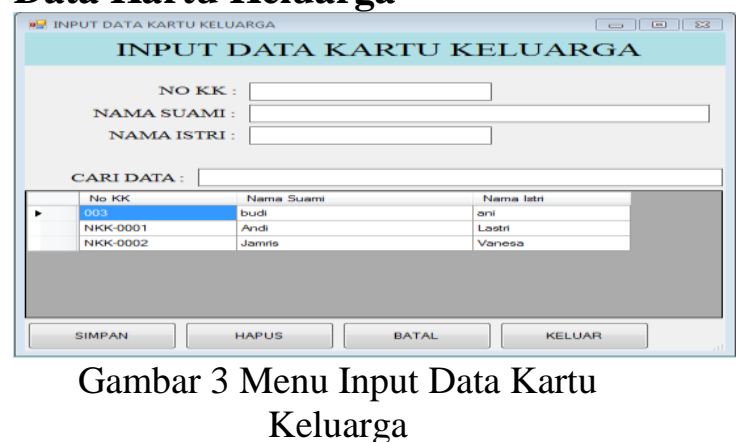




\section{Data Pekerjaan}

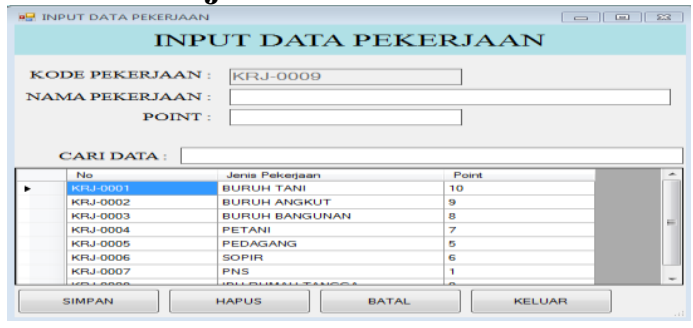

Gambar 4 Menu Input Data Pekerjaan

\section{Data Penghasilan}

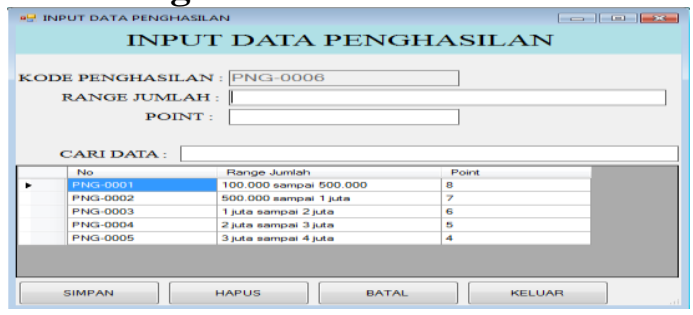

Gambar 5 Menu Input Data Penghasilan

6. Data Jenis Tanggungan

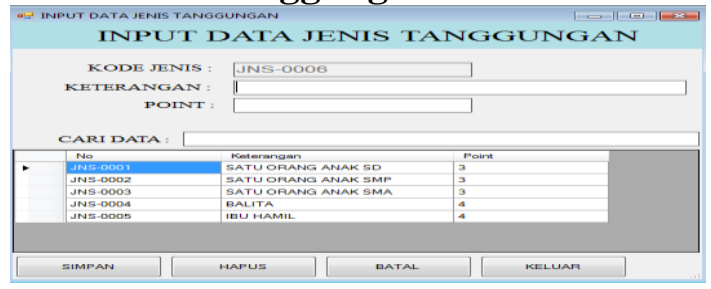

Gambar 6 Menu Data Jenis Tanggungan

\section{Menu Input Data Pemilihan}

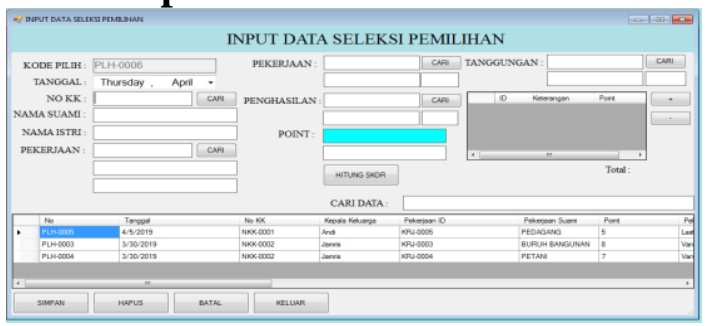

Gambar 7 Menu Input Data Pemilihan

8. Laporan Penerima PKH

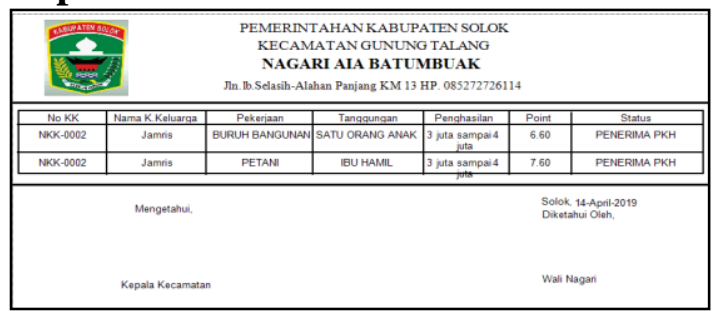

Gambar 8 LaporanPenerima PKH

\section{KESIMPULAN}

Sistem pendukung keputusan dalam menentukan penerima program keluarga harapan $(\mathrm{PKH})$ di Nagari Aia Batumbuak menggunakan metode AHP ini dapat dijadikan sebagai salah satu solusi dalam menyelesaikan permasalahan pemilihan calon penerima PKH. Dengan menerapkan beberapa kriteria yang ada seperti pekerjaan, penghasilan, dan jumlah tanggungan calon penerima, proses pemilihan calon penerima $\mathrm{PKH}$ dapat dilakukan dengan lebih akurat dan tepat sasaran dibanding dengan cara yang manual. Kesimpulan yang didapatkan dalam penelitian ini adalah sebagai berikut

1. Pengambilan keputusan untuk pemilihan calon penerima PKH ini menjadi lebih terperinci dan tepat sasaran agar tujuan pemerintah untuk mengurangi angka kemiskinan di Indonesia dapat terwujud.

2. Dengan menggunakan sebuah aplikasi dalam menentukan calon penerima PKH ini, maka akan menghindari masalah-masalah yang biasa terjadi jika keputusan diambil secara manual.

\section{DAFTAR PUSTAKA}

Al-Bahra Bin Ladjamudin. 2005. Analisa dan Desain Sistem Informasi. Yogyakarta. Penerbit : CV Andi Offset.

Alexander F.K.Sibero. 2011. Kitab Suci Web Programing, Yogyakarta. Penerbit : MediaKom.

Arbie. 2004. Manajemen Database dengan MySQL. Yogyakarta. Penerbit : Andi Offset.

Brady, M., \&Loonam, J. (2010). Exploring the use of entity-relationship diagramming as a technique to support grounded theory inquiry. Bradford : Emerald Group Publishing.

Irawan Dedi, Nurlaelli Mufrudhoh (2016). Analisis Sistem Pendukung Keputusan Untuk Pemberian Keputusan 
Pembebasan Biaya Bagi Siswa Yang

Kurang Mampu Menggunakan

Metode Simple Additive Weighting

(Study Kasus Mi Hidayatuul

Mubtadiin Srikaton Adiluwih). Jurnal

TAM (Technology Acceptance

Model). Volume 7.

http://www.ojs.stmikpringsewu.ac.id/i

ndex.php/JurnalTam/article/view/69

Jogiyanto. 2009. Analisi dan Desain

Sistem Informasi. Yogyakarta.

Penerbit : CV Andi Offset.

Jogiyanto. 2010. Analisis dan Desain

Sistem Informasi. Yogyakarta.

Penerbit : Andi Offset.

Mulyanto Agus. 2009. Sistem Informasi

Konsep dan Aplikasi. Yogyakarta.

Penerbi t: Pustaka Pelajar.

Nugroho. 2008. Konsep Pengembangan

Sistem Basis Data. Bandung. Penerbit

: Informatika.

Sutabri Tata. 2012. Konsep Dasar Sistem Informasi. Yogyakarta. Penerbit : CV Andi Offset.

Turban. 2005. Decision Support System and Intelligent System Edisi Bahasa Indonesia Jilid I. Yogyakarta. Penerbit : CV Andi Offset. 